\title{
Factors associated with ownership and use of written asthma action plans in North-West Melbourne
}

\author{
N.D. Sulaiman ${ }^{a, *}$, C.A. Barton ${ }^{b}$, M.J. Abramson ${ }^{b}$, T. Liawc, C. Harris ${ }^{d}$, \\ P. Chondros ${ }^{a}$, S. Dharmage ${ }^{e}$, D. Clarke $^{f}$
}

a Department of General Practice, The University of Melbourne, Broadmeadows Health Service, 35 Johnstone St, Broadmeadows Victoria 3047, Australia

b Department of Epidemiology and Preventive Medicine, Monash University, Australia

c Department of Rural Health, The University of Melbourne, Australia

${ }^{d}$ Centre for Clinical Effectiveness, Monash Institute of Health Services Research, Australia

e Department of Public Health, The University of Melbourne, Australia

${ }^{f}$ Department of Psychological Medicine, Monash University, Australia

Received 24 February 2004; accepted 26 April 2004

\section{KEYWORDS}

Asthma;

Paediatric;

Written asthma action

plans;

Questionnaires

\begin{abstract}
Summary
Purpose: Written asthma action plans (WAAPs) have become a core component of asthma management in Australia. We investigated ownership, utilisation and factors associated with ownership of asthma action plans by caregivers.

Methods: $443 / 776(57 \%)$ caregivers of children aged 2-14 years with asthma were identified from $32 \mathrm{GP}$ clinics as part of a randomised controlled trial (RCT), and completed self-administered questionnaires.

Results: Only $29 \%$ of participants owned a WAAP, while 13\% possessed verbal instructions, and $56 \%$ had no plan. An asthma action plan for children, which was developed by a general practitioner (GP) was more likely to comprise verbal instructions $(p=0.001)$, while action plans developed by paediatricians were more likely to be written ( $p<0.001$ ). Just over one half of caregivers. $59 \%$ ) reported discussing theic child's action plan the last time they visited their doctor for asthma. Factors associated with WAAP ownership included nightswaking $(p=0.013)$, selfreported severity $(p=0.001)$, and days lost from school $(p=0.037)$. Children who had seen a GP in the
\end{abstract}

\footnotetext{
* Corresponding author. Tel.: +6138344 4523; fax: +61393476136.

E-mail address: n.sulaiman@unimelb.edu.au
} (N.D. Sulaiman). 
last 3 months for asthma, or who had been to the Emergency Department (ED) or hospital were more likely to possess a WAAP $(p<0.001)$. Caregivers who were less satisfied with their child's asthma control were more likely to own a WAAP $(p=0.037)$. Caregivers with any action plan found it useful and $82 \%$ reported using their action plan for management of an acute attack. However, caregivers with a WAAP were more likely to adhere to the plan for an acute attack compared to caregivers with verbal instructions $(O R=4.5, p<0.05)$. Caregivers with a WAAP were more knowledgeable about asthma $(p=0.002)$, better able to recognise the difference between preventer and reliever medications $(p=0.01)$, and better able to recognise an asthma attack $(p=0.006)$.

Conclusions: Ownership of WAAPs in this group was still too low. Importantly, caregivers with written instructions were more knowledgeable about asthma and more likely to report following the action plan during an asthma attack.

(c) 2004 General Practice Airways Group. Published by Elsevier Ltd. All rights reserved.

\section{Introduction}

Written asthma action plans (WAAPs) have become a core component of asthma management in Australia. Ownership of written instructions for asthma management has been associated with a reduced risk of asthma mortality [1]. Similarly reductions in asthma morbidity have been reported when a WAAP is part of asthma management that includes education and regular review [2].

It has been suggested that health benefits may not be realised by all patients with asthma who are provided with written instructions [3]. We do not know what it is about WAAPs that are beneficial nor whether they are mostly useful for day to day management of asthma, or management of acute attacks [3].

As part of a larger randomised controlled trial of evidence-based asthma guidelines delivered to general practitioners via an education program, we took a combined quantitative and qualitative approach to investigate factors associated with ownership of written instructions for asthma, and the use and attitudes toward written asthma action plans by parents caring for children with episodic asthma. This paper describes the quantitative arm of the study. The qualitative findings Will be ree ported elsewhere.

\section{Methods}

This study draws on information from baseline data collected as part of an RCT of asthma guidelines implemented within an education package delivered to general practitioners (GPs) in Melbourne's Northern and North Western suburbs. Details of the RCT have been presented previously at conference (Proceedings of the 2002 General Practice and Primary Health Care Research Conference, pg.
$80)$ and will be published elsewhere. Briefly however (Appendix A), 65 GPs from 32 clinics in Melbourne's Northern and North Western suburbs were recruited through participating Divisions of General Practice. GPs were randomised into one of three intervention groups; the first group received a copy of asthma best-practice guidelines and attended two half-day workshops on management of asthma, the second group received a copy of asthma bestpractice guidelines, and the third group received ENT best-practice guidelines and attended two half-day workshops on treatment of these conditions.

Paediatric asthma patients managed by the GPs participating in the RCT were then identified from computerised medical records. Three practices were not computerised and patients were identified from local pharmacy records. The caregivers of children aged 2-14 years were mailed a questionnaire package at baseline and six months after the intervention to determine the health benefits to the children with asthma and their families.

The questionnaire package included an asthma knowledge questionnaire [6], questions about ownership and use of asthma action plans (Appendix B), as wetl as demographid land sociogeconomid

status.tion Prohibited

Data analysis

STATA version 7.0 (Stata Corporation, Texas) was used for analysis of questionnaire data. Categorical data were analysed using contingency tables. Chi-Square $\left(\chi^{2}\right)$, Odds Ratios and confidence intervals were used to determine associations between groups for ownership and use of asthma action plans. T-tests were used to determine differences between groups for asthma knowledge. A $p$-value $\leq$ 0.05 was required for statistical significance. 
Table 1 Summary of results.

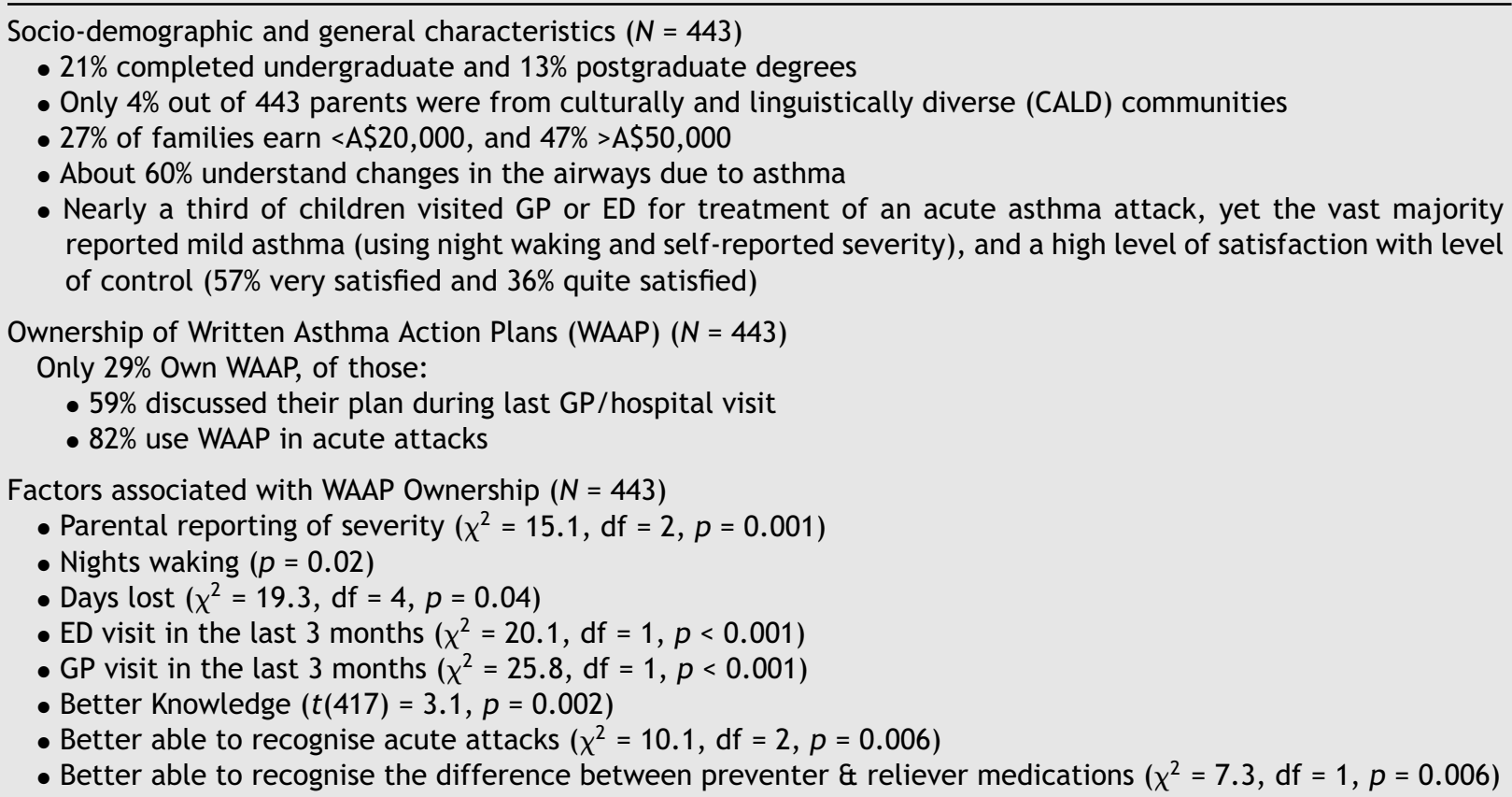

\section{Results}

Table 1 summarises the results. A total of 443 families completed the baseline questionnaire. English was the primary language spoken at home by caregivers (86\%) and children were predominately Australian born (95\%). Most caregivers had completed high school $(50 \%)$ or tertiary education $(39 \%)$, but $8 \%$ had not completed high school. Only 22 caregivers $(5 \%)$ reported that unemployment benefits were their primary source of income. One third of households had at least one adult smoker, but most participants reported that no one smoked in or outside of the home $(65 \%)$. Just less than one quarter $(24 \%)$ of caregivers (not including partners) reported that they also had asthma.

\section{Ownership of asthma action plans}

Only $29 \%$ of children possessed a WAAP, while $13 \%$ possessed verbal instructions, $56 \%$ had no plan for the management of asthma, and $2 \%$ did not answer this question in the questionnaire.

All caregivers with either a verbal or written action plan reported that they found the action plan useful and $82 \%$ reported using their action plan for management of an acute attack. However, caregivers with a WAAP were more likely to adhere to their plans for management of an acute attack com- pared with caregivers given verbal instructions only (OR $=4.5, p<0.05)$.

Asthma knowledge in this sample was quite low. Caregivers with a WAAP answered $56.8 \%$ of questions correctly (Mean \pm Standard Deviation $=12.5 \pm$ 0.18 , out of 31 questions) compared with caregivers who did not own a WAAP who correctly answered $52.3 \%$ of questions $(11.5 \pm 0.23)(t(417)=3.1, p=$ 0.002 ). This difference in knowledge although statistically significant, would not actually seem clinically important. Furthermore, higher proportion of caregivers with WAAPs was able to recognise the difference between preventer and reliever medications $\left(\chi^{2}=7.3, \mathrm{df}=1, p=0.007\right)$, and recognise an asthma attack $\left(\chi^{2}=10.1, \mathrm{df}=2, p=0.006\right)$.

\section{Factors associated with WAAP ownership}

\section{Who generated the action plan?}

Children who had seen a GP in the last 3 months for asthma $\left(\chi^{2}=25.8, \mathrm{df}=1, p<0.001\right)$, or who had been to the emergency department (ED) or hospital $\left(\chi^{2}=20.1, \mathrm{df}=1, p<0.001\right)$ were more likely to possess a WAAP. Children whose action plans were developed by a GP were more likely to report being given verbal instructions $\left(\chi^{2}=13.8, \mathrm{df}=1, p\right.$ $=0.001$ ), while plans developed at a hospital or by paediatricians were more likely to be written $\left(\chi^{2}=\right.$ 


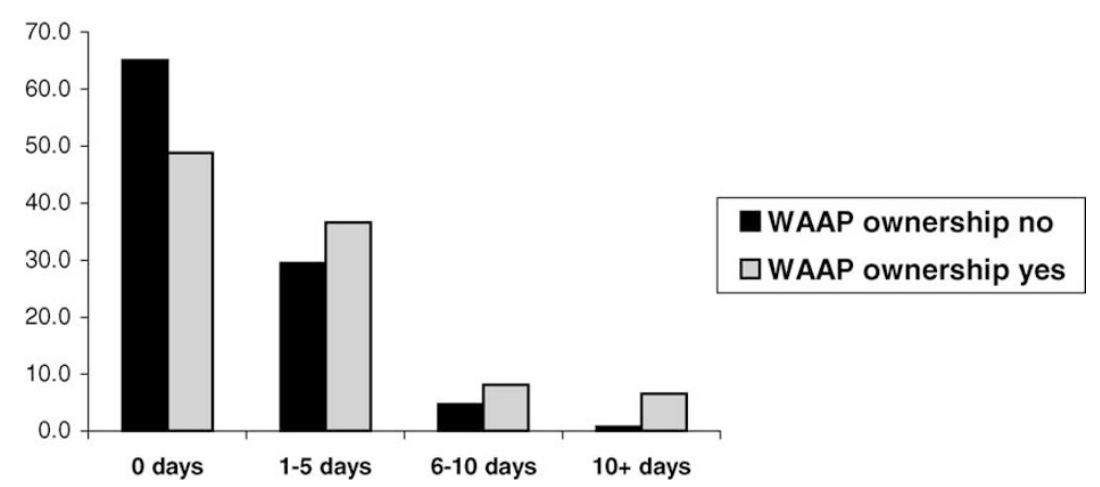

Figure 1 Work/school days missed because of asthma and (\%) ownership of written asthma action plan (WAAP) $(P=0.04)$.

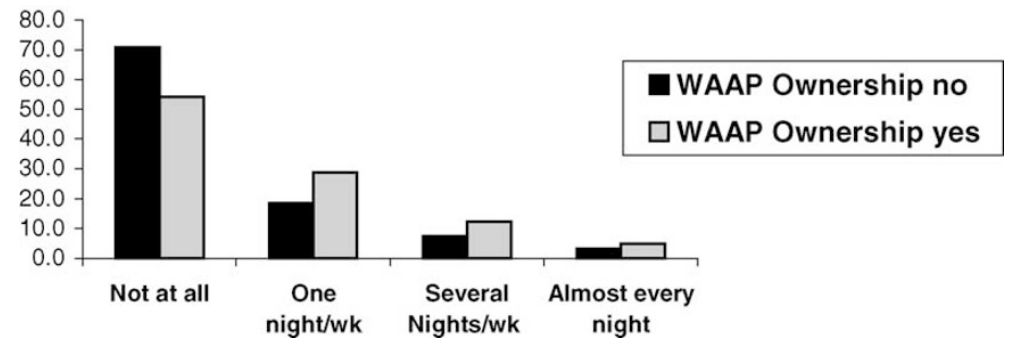

Figure 2 Frequency of night waking because of asthma symptoms and (\%) ownership of written asthma action plan (WAAP) $(P=0.02)$.

$22.4, \mathrm{df}=1, p<0.001)$. Just over half $(59 \%)$ of parents who owned a WAAP reported discussing their action plan the last time they visited their doctor for asthma (Table 1).

\section{Asthma severity}

Written instructions were more likely to be possessed by children who reported missing one or more days of school (Fig. 1) $\left(\chi^{2}=19.3\right.$, df $=4, p=$ 0.001 ) or who woke several nights (Fig. 2) or more a week $\left(\chi^{2}=10.7, \mathrm{df}=3, p=0.013\right)$. However, 30 children $(7 \%)$ who reported waking several nights a week or more (i.e. had persistent asthma) had not been given a WAAP. Caregivers were more likely to have a WAAP if they reported their child's asthma was moderate (Fig. 3 ) or severe $\left(\chi^{2}=15.1, \mathrm{df}=2\right.$ $p=0.001$ ), or if they were not satisfied with their child's asthma control $\left(\chi^{2}=9.5, \mathrm{df}=3 p=0.037\right)$.

\section{Demographic and socio-economic status}

There were no differences in ownership of action plans based on demographic or socioeconomic

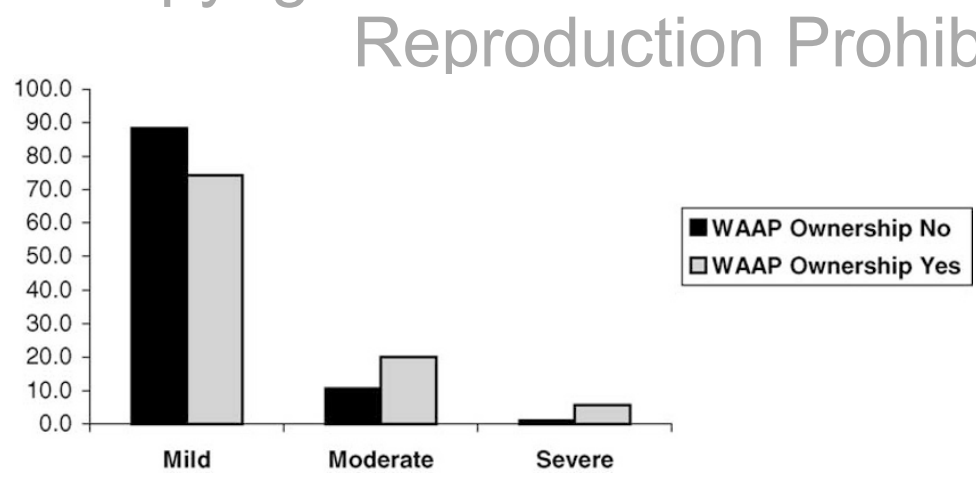

Figure 3 Self-reported asthma severity and $(\%)$ ownership of written asthma action plan (WAAP) $(P=0.001)$. 
factors including employment, caregiver education, household income or child's country of birth.

\section{Discussion}

Ownership of asthma action plans in this group was still too low, and some children with persistent asthma did not possess any action plans for their asthma. Importantly, caregivers with written instructions were more knowledgeable about asthma, and more likely to report following the action plan during an asthma attack.

National guidelines for management of asthma have consistently recommended that all individuals with asthma should have a written individualised plan of how to treat deteriorating asthma. However, studies of WAAP ownership in the community have shown that WAAP ownership remains sub-optimal, with rates of ownership ranging between $34.7 \%$ in a NSW study [7] and $13.3 \%$ in Melbourne adults [8]. As with the earlier Melbourne study [9] verbal instead of written instructions for asthma were more likely to be given to participants by GPs. However, in the current study, more than half the caregivers who had a WAAP reported discussing their child's action plan at their last medical visit. This may reflect more frequent changes in medication regimens for children with asthma, whereas adults with asthma might be expected to be on a more stable medication regimen.

While there is evidence for the effectiveness of written asthma action plans [2], especially in combination with education and regular review, a potential confounding factor is whether patients actually use their written action plans. Qualitative reports of patients use of and attitudes toward WAAPs suggest they are often not utilised as intended by adult patients [5], or are not utilised at all [4]. In the current study, more than three quarters of participants with an action plan reported using their action plan for management of an asthma attack, but we were unable to determine whether patients followed their plans accurately, or if they had modified the instructions as has been reported previously in qualitative studies of adult asthma patients [5].

Caregivers in this study who had been given written instructions were more knowledgeable about asthma, more likely to know the difference between reliever and preventer medications and better able to recognise an asthma attack. While there are age related developmental goals for asthma management, it can only benefit both child and caregiver that the WAAP be used to educate the child about asthma management. We have reported previously that caregivers who are more knowledgeable about asthma have children who are more knowledgeable about asthma [9], and asthma education has been shown to reduce asthma morbidity [10]. Subsequently, it might benefit families if WAAPs utilised language that could be understood by primary school aged children. This was also highlighted in a recent study [11], which suggested that health care providers who incorporate information that parents have given them will be more successful in creating a mutually formulated treatment plan.

The limitations of this study are the same for many cross-sectional studies and we are unable to draw causal inferences. Furthermore, participants were drawn from a general practice population and had predominately episodic asthma with mild to moderate attacks, so whether the factors related to ownership and use are the same as those for patients with persistent asthma or those who have had severe attacks needs to be investigated further.

This study highlights a number of opportunities by which health professionals can improve their management of paediatric asthma. A small number of children with persistent asthma symptoms did not possess a written asthma action plan. As a group, too few children possessed a written asthma action plan, with GPs being less likely than hospital doctors or specialists to provide a written plan for children. Similarly, too few families reported discussing their action plan with their doctor at their last consultation. Yet, there were clear benefits to patients with written instructions in terms of asthma knowledge and management of acute attacks. Ownership and use of written asthma action plans needs to be improved in line with best practice guidelines.

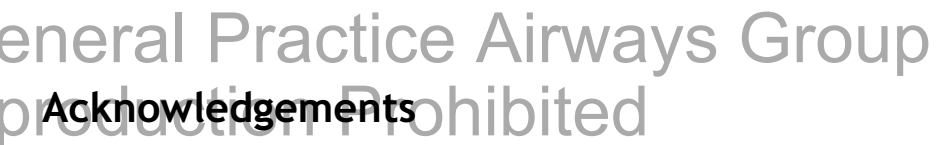

The project was supported by a GlaxoWellcome Respiratory Clinical Research Awards 2000/01. We are grateful to Susan Sawyer and Colin Robertson who gave their time so generously, as members of the reference group, and to all GP and patients and Northern and North West who participated in the project. 


\section{Appendix A. Study methodology and flow chart}

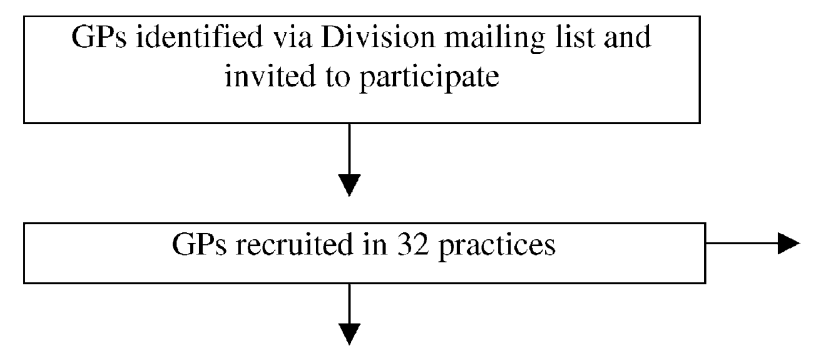

65 GPs completed baseline questionnaire

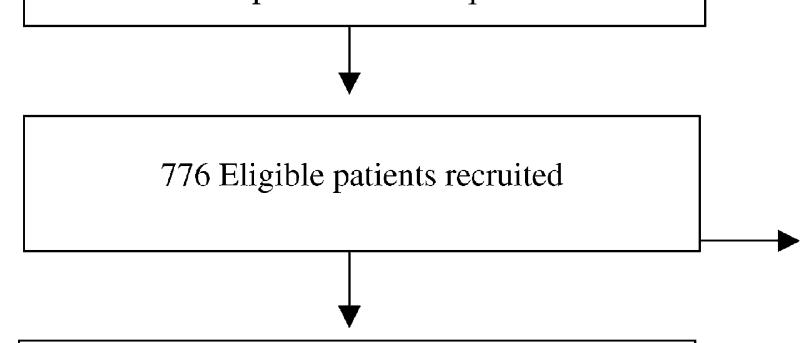

$443(57 \%)$ Patients completed baseline questionnaires

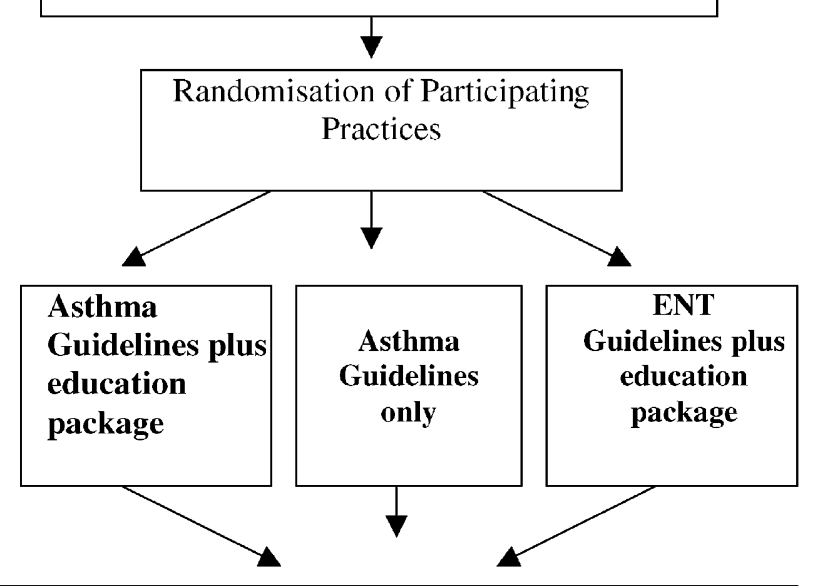

Second survey 6 months after intervention - GPs and Patients

\section{GP inclusion criteria}

- A minimum of $50 \%$ of GPs in the practice enrol in the study

- All GPs in the practice agree to support the study even if not enrolled as participants

- Participating GPs agree to:

- Be randomised to one of three groups

- Complete three questionnaires

- Attend two 3-hour education sessions

- Assist research team to identify children with asthma attending the practice

- Allow team access to medical records

\section{Patient inclusion criteria}

\section{Child}

- Aged 2-14 years

- Asthma diagnosed or bronchodilators prescribed by GP

- Visited practice during the preceding 6 months

- No other chronic conditions (e.g heart disease, cancer, cystic fibrosis)

Parents

- Understand English

- Agree to complete three questionnaires

- Agree to allow access to their medical record

\section{Copyright General Practice Airways Group Reproduction Prohibited}




\section{Appendix B. Questions about asthma action plan}

\section{ACTION PLAN}

An Asthma Action Plan is a written set of instructions, which tells you what medicines your child should be taking and what to do if your child is having an asthma attack or their symptoms are getting worse. An Action Plan is sometimes called a Management Plan. (Please tick only one box per question)

1. Do you have an Asthma Action Plan?

$\square$ Yes $\square$ No (Go to Part C)

2. Is the Asthma Action Plan written down?

$\square$ Yes $\square$ No

3. Where did you get it from?

Your child's GP
Hospital/Paediatrician
Other, please specify........................

4. Did your GP or clinic nurse discuss the Asthma Action Plan the last time you attended the clinic for asthma? $\square$

$\square$

$\square$ Yes $\square$ No

5. Do you use the Asthma Action Plan for your child's everyday asthma care?

$\begin{array}{ll}\square \text { All } & \square \\ \text { the time } & \text { Sometimes }\end{array}$

$\square \quad$ Never

6. Has your child had an asthma attack in the last THREE MONTHS

$\square$ Yes $\square$ No

If yes, did you use your Action Plan?

$\square$ Yes $\square$ No

7. How useful did you find the Asthma Action Plan?

(Please circle the most appropriate number from 1 to 5 with one being the least useful and five being the most useful ):

$\begin{array}{lllll}\text { Not useful } & & & & \text { Very useful } \\ & 2 & 3 & 4 & 5\end{array}$

\section{References}

[1] Abramson M, Bailey M, Couper F, et al. Are asthma medications and management related to deaths from asthma? Am J Respir Crit Care Med 2001;163:12-8.

[2] Gibson P, Powell H, Coughlan J. Self-management education and regular practitioner review for adults with asthma. Cochrane Database of Systematic Reviews 2003:3. H

[3] Sawyer S. Action plans, self monitoring and adherence: changing behaviour to promote better self-management. MJA 2002;177(Suppl):S72-4.

[4] Jones A, Pill R, Adams S. Qualitative study of views of health professionals and patients on guided self management plans for asthma. BMJ 2000;321:1507-10.

[5] Douglass J, Aroni R, Goeman D, et al. A qualitative study of action plans for asthma. BMJ 2002;324:1003-8.

[6] Fitzclarence CA, Henry RL. Validation of an asthma knowledge questionnaire. J Paediatr Child Health 1990;26:200-4.
[7] Marks G, Jalaludin B, Williamson $M$, et al. Use of preventer medications and written asthma management plans among adults with asthma in New South Wales. Med J Aust 2000;173:407-10.

[8] Matheson M, Wicking J, Raven J, et al. Asthma management: how effective is it in the community? Internal Medicine Journal 2002;32(9-10):451-6.

[9] Barton CA, Abramson "MJ, Aroni R," et al, What determine knowledge of asthma among young people and their families? J Asthma 2002;38(8):701-9

[10] Guevera J, Wolf F, Grum C, et al. Effects of educational interventions for management of asthma in children and adolescents: systematic review and meta-analysis. Bmj 2003;326:1308-14.

[11] Peterson-Sweeney K, McMullen A, Yoos HL, et al. Parental perceptions of their child's asthma: management and medication use. Journal of Pediatric Health Care 2003;17(3):118-25.

Available online at www.sciencedirect.com

science $\mathcal{Q}$ Direct? 